\title{
THE COMPLIMENT AS A SOCIAL STRATEGY: A DISCOURSE ANALYSIS OF ON-LINE COMPLIMENTS AND INSULTS
}

\author{
Joe Gregory Ocaña Loor \\ Email: joe_gol@hotmail.com
}

Received: November 2, 2019

Accepted: December 2, 2019

\begin{abstract}
Compliments and insults play an important role in our daily lives, and even more when a high part of it is in social networks. Some authors have focused on research on responses to compliments (Holmes, 1986) responses to compliments online (Maíz-Arévalo, 2013), compliments in Japanese (Adachi, 2011), or compliments in audio-recorded, face-to-face conversations (Maíz-Arévalo, 2012). Nevertheless, little research has been done on how English compliments and insults are constructed in the comments section of famous people posts in social media. This is the aim of this text, as well as answering the following questions: what kind of compliments do fans use? What kind of insults do users employ? Do they change depending on the sexual preference of the celebrity that social networks users address? Results display that compliments and insults can be used explicitly and implicitly, although the explicit way is the most frequent type, both among compliments and insults. Also, regarding the sexual preference of celebrities, we can find that a there is a low influence over social media users when complimenting and insulting famous individuals in social networks.
\end{abstract}

Keywords: compliments, insults, social networks, English, celebrities, Facebook, post.

Resumen: Los halagos e insultos desempeñan un papel importante en nuestra vida cotidiana, incluso más cuando gran parte de ella está publicada en las redes sociales. Algunos autores se han centrado en investigar las respuestas a halagos, respuestas a halagos en línea, halagos en japonés o halagos en conversaciones cara a cara grabadas en audio. Sin embargo, poco se ha investigado acerca de cómo se construyen los halagos en insultos en inglés a lo largo de la sección de comentarios de las publicaciones de famosos en redes sociales. Este es el objetivo de este texto, así como responder a las siguientes preguntas: ¿Qué tipo de halagos usan los fans? ¿Qué tipo de insultos se usan? ¿Cambian dependiendo de la orientación sexual de los famosos? Los resultados demuestran que los halagos e insultos pueden ser usados explícitamente e implícitamente, aunque la forma más común es la explícita, tanto en halagos como en insultos. Además, en cuanto a la orientación sexual de los famosos, vemos que los usuarios de redes sociales se ven poco influenciados a la hora de halagar o insultar a famosos -Donald Trump y Neil Patrick Harris- en redes sociales.

Palabras clave: halagos, insultos, redes sociales, inglés, celebrities, Facebook, publicación. 


\section{INTRODUCTION}

With the creation and popularisation of social networks such as Facebook, we can find that the amount of people that actively uses Facebook worldwide has increased from 100 million in 2008 , to around 2129 million in $2018^{1}$. In social networks, famous people have found a way to be in the spotlight, and their fans, a way to follow everything they do in their daily life. Due to this interaction, we can usually see fans commenting on official sites or social networks posts of famous people. We can even see how fans start arguing in the comments section of their posts because of some compliments or insults that another person previously wrote in this section. Because of this, I will pay attention to how fans construct compliments in English so that they can use them in favour of worldwide known people in social networks. As well as compliments, I will observe how insults are constructed by social networks users in order to be used against these famous individuals.

Studies have been carried out in areas such as responses to compliments (Holmes, 1986) responses to compliments on-line (Maíz-Arévalo, 2013), compliments in Japanese (Adachi, 2011), or compliments in audio-recorded, face-to-face conversations (MaízArévalo, 2012). However, little research has been done on how English compliments and insults are constructed in the comments section of famous people posts in social media. Therefore, my research objective for this work is to know how compliments and insults are built in social networks posts and which functions they have. More specifically, I will attempt to answer the following research questions: What kind of compliments do fans use? What kind of insults do users employ? Do they change depending on the sexual preference of the celebrity that social networks users address? My hypothesis is that the presence and functions of compliments and insults may be sensitive to the sexual preference of the chosen famous characters.

After this introduction, the sections contained in this paper that can be found are five: theoretical background, method, results and analysis, conclusion, and references. The first section deals with the theories, concepts and notions used to understand the main focus and analysis of this work. The second section discusses the process of collecting and selecting the sample data utilised in the results and analysis section. This section, results and analysis, focuses on the analysis of the chosen samples and the results that we obtain from them. The conclusion section deals with the answer of the research questions made in the introduction as well as a summary of the results found.

\section{THEORETICAL BACKGROUND}

\subsection{SPEECH ACTS}

The first category to be dealt with in the theoretical background section is speech acts. Austin (1962) stated that a speech act is making an utterance, or an action performed through

1 "Number of Monthly Active Facebook Users Worldwide as of 4th Quarter of 2017 (in millions)", 2018, https://www.statista.com/statistics/264810/number-of-monthly-active-facebook-users-worldwide/ 
speech. Yule (1996: 47) explains that, normally, speakers expect speakers to recognise their speech act, and in order for this to happen, the participants of the conversation are normally helped by the circumstances around the utterance. These circumstances, together with other utterances, have been termed the speech event. In Yule's (1996: 48) own words, "it is the nature of the speech event that determines the interpretation of an utterance as performing a particular speech act". For instance, if we imagine a situation in which the speaker is going into a restaurant during a summer day and he/she produces the following utterance, it is likely to be interpreted as a complaint:

- $\quad$ It is so warm in here!

Nevertheless, if we change the circumstances around the utterance to a quite cold night during the winter in a Nordic country, the previously mentioned utterance would be interpreted as praise. Furthermore, in order to give a classification of speech acts, Searle (1976) suggests there are five types of general functions that speech acts perform, with their corresponding definitions -although I have provided different examples exclusively for the current paper-. These functions are: declarations, representatives, directives, commissives, and expressives.

Declarations are speech acts that change the world when they are uttered. In order to perform a declaration successfully, the speaker must have a special institutional role, in a specific context (Searle, 1976). To clearly understand this, we can imagine the following examples:

1. Boss: You are fired.

2. Judge: Case closed!

In both of these examples, the speaker is changing the state of the hearer or the situation. In example 1, since the exact moment that the boss states the employees are fired, they are no longer working on the company. Also, in example 2, the case is closed since the judge states so.

Additionally, we can find representatives. Representatives are those speech acts which say what the speaker believes to be the case or not. Speakers can represent the world as they believe it is through assertions, statements of fact, descriptions or conclusions (Searle, 1976). We can think of examples of representatives such as the following ones:

1. It was a cold night.

2. The Earth is round.

Regarding example 1, in the same place and time, perhaps another person thought that is was a warm night. And in example 2, maybe someone believed that he Earth was flat; however, both examples show how their corresponding speakers depicted the world as they think it was.

As well as declarations and representatives, we can find directives. Directives are speech acts that speakers employ in order to get someone to do something. They are used to 
express the speaker's will. Amongst directives, we can find suggestions, orders, commands, or requests, which can be negative or positive (Searle, 1976). Two directives that we can think of can be found below:

1. The hearer has recently mown the grass and addresses the hearer with the following sentence: Don't step on the grass.

2. While walking in the city centre, the hearer, who has forgot his jacket at home, asks for the hearer's clothes with the following question: Can you lend me your jacket?

The first example shows an order which is used by the speaker to avoid the hearer from ruining the grass. There is no choice for the hearer whether to step or not on the grass. The second example, on the contrary, shows a request which the hearer can accept or decline.

Furthermore, commissives are also included in the list of speech acts by Searle (1976). Commissives are speech acts which are employed by speakers in order to commit themselves to a future action. The intention of the speakers is expressed through them, and in order to do this, speakers can use pledges, threats, refusals, or promises, which can be performed by the speaker as a part of a group, or by the speaker alone (Searle, 1976). To identify them more clearly, we can look at the following examples:

1. I will not go that way.

2. We are going to come back.

Examples 1 and 2 show the speaker's intention, although example 1 uses a first-person singular pronoun, and example 2 uses a first-person plural one. Therefore, the plan in example 1 will be performed by the speaker alone, and the one in example 2 will be carried out by the speaker as a part of a group.

Finally, the last type of speech acts is expressives. Searle (1976) states that expressives are speech acts which say what the speaker feels, and they may be performed through the use of statements of pain, pleasure, sorrow, joy, dislikes, or likes. Taavitsainen and Jucker (2010) agree on this definition, but they add that this type of speech acts also express the state of mind of the speaker, as well as his/her attitudes. In addition, Searle (1976) points out that expressives convey psychological conditions, but Norrick (1978: 279) limits this statement and argues that they do "not express beliefs or intentions, which arise to given states of affairs". Regarding the source, expressives can be caused by something one of the participants of the conversations does, although they are exclusively related to the experience of the speaker (Searle, 1976). The examples below can be used to identify expressives:

1. I'm so sad for that!

2. Fantastic, mmm, yes!

The first example is used to express the sorrow of the speaker about something the hearer has got. The second one, on the contrary, is employed to express the joy that the speaker feels. Both examples of expressives are related to the experience of the speaker, even if the hearer has something to do with it. 
From these previously mentioned speech acts, this paper will exclusively focus on expressives, and more specifically, on compliments and insults.

\subsection{EXPRESSIVES: COMPLIMENTS}

Al-Azzawi (2011: 111) defines compliments as "speech acts which maintain, improve or support the addressee's face". In order to make this definition clearer, we need to understand the notions of politeness and face. Eelen (2014) claims that politeness is showing that someone has consideration for another person, or having good manners, what can be simplified as showing awareness of other people's face. Face, the second important term to understand compliments, is defined by Brown and Levinson (1987) as the public image which every person wills to claim for her/himself. Moreover, Brown and Levinson (1987) argued that face can be divided into positive and negative face. On the one hand, a person's positive face is the positive self-image or personality that is claimed by the participants of an interaction, and which is expected to be approved by the rest of participants (Brown and Levinson, 1987). On the other hand, a person's negative face is the rights to non-distraction, personal preserves, and basic claim to a territory (Brown and Levinson, 1987). As basic wants, the maintenance of each other's face is one of the main interests for human beings to achieve during interactions, since every participant knows what every other participant desires (Brown and Levinson, 1987). Therefore, there is a strong relation between face and politeness:

Behaviour which avoids imposing on others (or avoids 'threatening their face') is described as evidence of negative politeness, while sociable behaviour expressing warmth towards an addressee is positive politeness behaviour (Holmes, 2013: 5)

Having made clear the basic notions of face and politeness, we need to widen the definition of the previously stated compliments. In particular, Holmes (1988) argues that compliments explicitly or implicitly give credit to another participant different from the speaker, who is usually the participant that is being addressed. In line with Holmes (1998) and Al-Azzawi (2011), Adachi (2011) distinguishes between explicit and implicit compliments. She claims that explicit compliments are the ones where speakers employ the literal meanings encoded in words or phrases, while implicit compliments are those which use non-conventional meanings that can highly vary depending on the context of the conversation exchange (Adachi, 2011). In order to exemplify these two categories of compliments, I provide two examples below:

Example 1: You shirt is amazing! (Explicit)

Example 2: Your girlfriend is lucky to have you. (Implicit)

The first statement is clearly an explicit compliment, as the literal meaning of the adjective "amazing" is being used by the speaker to approve the hearer. The second example is an implicit compliment since the speaker compliments the hearer, even though the addresser is not using any word to approve the addressee. At first, it could seem that 
the speaker is complimenting the girlfriend of the hearer, as she is the one "being lucky". Nonetheless, the actual complimentee is the hearer in this conversation, as she/he has some qualities that make her/his girlfriend lucky to have her/him.

Besides Holmes and Adachi, Boyle (2000) deals with explicit and implicit compliments, although including the Gricean maxims ${ }^{2}$. Through an idea similar to Adachi's, Boyle (2000) claims that a small set of conventional formulae is what makes the performance of explicit compliments successful. However, implicit compliments are not only influenced by the context of the conversational exchange, but also by Grice's maxims (cooperative principle) in order for their correct performance (Boyle, 2000). The following examples illustrate Boyle's claims:

Example 1: You are incredible! (Explicit)

Example 2: Your mother has a really nice daughter. (Implicit)

Example 1 shows a small set of conventional formulae which can be clearly identified as an explicit compliment when it is heard. The second example does not follow a conventional formulae used to approve the hearer, therefore, it is an implicit compliment. If the conversational contribution would not have been made such as is required, at the stage at which it occurs, and by the accepted purpose of the exchange in which the participants are engaged, the status of Example 2 being an implicit compliment would have changed. Furthermore, Al-Azzawi mentions that compliments are "social lubricants which create or maintain rapport, i.e. strategies that aim to establish or reaffirm common ground, mutuality or social solidarity" (Al-Azzawi, 2011: 113). Consider the following example:

- Speaker: Such a kind daughter you have!

- Hearer: Thanks!

Even though the facts uttered in the conversation which just occurred may not be true, they were used in order to establish a friendly environment between the speaker and the hearer.

Having observed the definitions from the previously mentioned authors for the term "compliment", I can suggest a more complete definition for this word:

Compliments are speech acts which maintain or improve another participant's face, who is usually the hearer, and which may also create rapport among the participants. They can be explicit, if they are formed by a small structure of words with literal meanings, or

2 Grice's (1991: 26) cooperative principle says that the participants of a conversation should aim to make their conversational contribution "such as is required, at the stage at which it occurs, by the accepted purpose" of the exchange in which they are engaged. This is achieved through the use of the maxim of quality, by saying only what participants believe to be true; the maxim of quantity, by making their contribution as informative as required for the particular purpose; the maxim of relation, by making a contribution relevant to the interaction; and the maxim of manner, by being clear in what participants say, avoiding ambiguity or obscurity, and being brief and orderly in their contribution to the interaction (Grice, 1991). 
implicit, if they do not follow a conventional structure and are highly influenced by the context when identifying them.

Focusing on the characteristics of compliments, Holmes (1988) provides some features that make compliments different from other speech acts. She claims that compliments are employed because of a good skill, characteristic, or possession-amongst other reasons- that is appreciated by both the hearer and the speaker (Holmes, 1988). Related to this statement, it can also be observed that praise and admiration are expressions which are found as a result of the use of compliments (Herbert, 1990). Nevertheless, praise and admiration are not always synonyms for compliment. Contrary to the statements put forward by Holmes and Herbert, Al-Azzawi (2011) argues that if a compliment is understood as too far from reality, it will be heard as a sarcastic or ironic scorn. Consider the following example:

Speaker: You sing so well!

The employment of the previous statement in a situation where someone is singing badly is totally the opposite of a compliment. It clearly shows how the speaker is making fun of the hearer, through the use of sarcasm.

In line with Al-Azzawi, Brown and Levinson (1987) maintain that the use of compliments which imply certain envy and desire to get what the hearer has can be considered a face-threatening act ${ }^{3}$. For instance, if we imagine a speaker stating "Your drink looks really nice!" we can infer that he/she may say so because he/she desires the drink. Therefore, the speaker does not only state the previous sentence in order to compliment the hearer, but also because he/she wishes to taste it.

However, giving compliments is not always the difficult task to carry out during conversations. Hearers who receive compliments can create uncomfortable situations if they do not deal with them properly. In her study on compliments online, Maíz-Arévalo (2013) claims that complimentees can choose to ignore the compliment and respond to the main topic (if the compliment is an aside thought). Other options, she argues are introducing a new topic or going back to a previous one. The result of this is showing modesty, as it can be shown in the example that I provide below:

User 1: You look gorgeous!! Where are those shoes from??

User 2: I love those shoes! Where did you buy them?

User 3: They are from the shop next to the post office.

User 3 in this conversation has uploaded a picture showing his outfit. He receives compliments on his shoes and questions about where he bought them. Nonetheless, he does not respond to the compliments. Instead, he follows the conversational thread by only answering to the question that User 1 and User 2 performed, what may be interpreted as a sign of modesty.

3 Brown and Levinson (1987) define a face-threatening act as an act which is contrary to the face wants of a participant of a conversation. They can threaten the face of the hearer or the face of the speaker, and they can threaten the negative face or the positive face. 


\subsection{EXPRESSIVES: INSULTS}

Participants of conversations may not only use words to make interlocutors feel good, but also may use them as weapons. Thus, positive politeness strategies such as compliments previously mentioned are not always followed, and one of the main ways to avoid these strategies is by insulting. Since the aim of insulting is to offend, or to treat with insolence or indignity ("insult", n.d.), we can see a clear connection with impoliteness. Culpeper (2005) relates impoliteness to the following:

1. Impoliteness comes about when the speaker communicates face-attack intentionally.

2. Impoliteness comes about when the hearer perceives and/or constructs behaviour as intentionally face-attacking.

3. Impoliteness comes about in a combination of 1 and 2 .

Focusing on the second definition, Bravo (2003) also maintains that it is not right to talk about an impoliteness effect if the hearer does not understand the statement as intentionally threatening. In the same vein, Eelen (2001) claims that the interlocutor has to perceive the context as impolite. If this occurs, then the interlocutor can interpret it as impolite. Therefore, the conclusion that we get from these authors is that the feeling of a speaker being impolite to you is only achieved if you perceive his/her utterance as impolite. In order to explain this further, I provide the following example: in a Facebook post, User A uploads a picture in which he appears showing a nice outfit. His friend, User B comments "You look so ugly!" Considering the friendship they have, and the irony of the comment, Friend A does not feel offended. Instead, he perceives Friend B's comment as a compliment (implicit) and not as an insult. This shows how a comment, which per se may be considered offensive, is not perceived as such by the hearer because of the context. However, to understand both this example and situations in which insults are actually compliments -or vice versa-, we need to explain the notion of irony. Irony is the employment of words to express especially the contrary of the literal meaning ("Irony", n.d.).

Having understood what irony is, we can move further into insults. According to Mateo and Yus (2013) insults usually come from words that did not have an original scornful meaning but that were added a connotative layer which conveys insulting and non-insulting overtones. This results in offensive metaphors such as pig, which is literally an animal, but has the connotation of dirty, untidy, and the metaphoric meaning of someone with dirty manners or behaviour (Mateo and Yus, 2013). As well as offensive metaphors, Mateo and Yus talk about insults which have been deliberately created with a specific insulting intention. For instance, they mention the word asshat, which is used to compare the buttocks of a person with her/his brain. It is also the case of moobs, which means a man with boobs, according to Mateo and Yus. In addition, Hughes claims that there are other insults which have kept the offensive power of the word without suffering a decrease in intensity, as in the case of the term whore (Hughes, 2006).

Regarding lexical fields related to insults, Fernández-Fontecha and Jiménez-Catalán (2003), as well as Mateo and Yus give several ones. In order to exemplify them, I will provide some examples. Fernández-Fontecha and Jiménez-Catalán (2003) mention the existence of 
insults relating humans and animals metaphorically, such as the previously mentioned pig. Mateo and Yus (2013) expand the list of lexical fields with words and expressions related to sex, such as fuck you. Moreover, they mention insults whose target are relatives. For instance, son of a bitch will be part of this category. Also, Mateo and Yus include expletives which downgrade people's intellectual abilities, such as you are retard, and insults which are focussed on race, religion, gender, or nationality. From the last ones we can think of frog, which is an offensive word to refer to a French person, or nigger, that is remarkably offensive for a black person ${ }^{4}$. Additionally, Mateo and Yus mention insults related to the lexical fields of human excretion, like you are shit, or swearwords such as motherfucker.

Although the literature about insults is extremely wide, this section has compiled the relevant studies to contextualise the analysis in section 4 . .

\section{METHOD}

\subsection{DATA COLLECTION}

As I already pointed out, I will observe how social networks users employ compliments and insults in posts of famous people. In order to achieve my goal, I needed social networks that I could use as a source of pictures and comments, and accounts of two well-known characters that could be useful for this aim. Regarding social networks, Facebook has been chosen over other social networks (e.g. Instagram, Twitter, etc.) because of different reasons. Facebook shows to have a higher amount of comments from fans per picture, and a higher number of replies for each of the comments, making the pictures have several long threads under them. On my search for social networks, the ones that were not Facebook, such as Twitter or Instagram, were also inspected in the search for posts with useful comments to analyse. However, they were discarded due to the lack of samples, or because the few samples found were not as good enough to be analysed as the ones collected from Facebook. Additionally, the collection of posts from Facebook to be used in the analysis of this paper required the appearance of compliments and insults, both explicit and implicit. Posts which did not include any compliments or insults have been discarded from the collection.

Regarding the collection of social networks accounts, I took a closer look at famous people like the singers Rob Halford and Sam Smith, the football player Cristiano Ronaldo, and the artist Joe Jonas. They had some of the requirements I set up for this paper, such as being world-known people, with accounts in social networks. Nonetheless, it seemed that some of these celebrities were not the ones in charge of their accounts.

After looking at these previously mentioned celebrities, the accounts of Donald Trump and Neil Patrick Harris were found in Facebook. Even though they do not belong to the same "group"-as the first one is a politician and the second one is an actor-, they were chosen due to various reasons. Both Trump and Patrick Harris used their own social networks profiles, without any community manager management, and both are world-wide known characters.

4 “Offensive Words for People According to Nationality or Ethnicity", (n.d.) 
In order to understand my choices, we need to get into more details and look at the biographies of the chosen people. According to the website Biography.com ("Donald Trump", 2018), Donald John Trump (June 14 ${ }^{\text {th }}, 1946$ ), is the 45 th and current President of the United States since $20^{\text {th }}$ January, 2017. Before this event, he was a real estate mogul, as he had been involved in profitable building projects in Manhattan. Additionally, he became a TV star starring shows such as The Apprentice or The Celebrity Apprentice. Trump began his politics career in 2015 when he became a member of the Republican Party, and later, on $19^{\text {th }}$ July, 2016, he turned into the official Republican candidate for president of the United States. On November, 2016, Donald Trump was elected President of the United States. He has become a polemical celebrity because of different topics such as the "Access Hollywood" controversy, Russian hacking, the wall with Mexico, gun control in the United States, the recognition of Jerusalem as capital of Israel, his common use of social networks, and the relationship with his wife, Melania Trump, amongst several other reasons.

With regard to the second celebrity, Neil Patrick Harris, and according to Biography.com (2015), Neil Patrick Harris (June 15 th 1973 ) is a well-known actor who "has starred in TV shows such as Doogie Howser, M. D. or the successful sitcom How I Met Your Mother, and performed on stage in productions like Cabaret'. He is openly gay since its announcement in 2006, and he is married to David Burtka, with whom he is father of twins since October 12 $2^{\text {th }}, 2010$. As Reporter (2011) affirms, in How I Met Your Mother, Neil Patrick Harris plays a womaniser male character that has nothing to do with the real Neil Patrick Harris, hence, this can create some confusions amongst his fans.

As it is noticeable from the previous paragraphs, Donald Trump is a heterosexual celebrity, and Neil Patrick Harris, a homosexual one. This choice was not impromptu, as one of my goals for this analysis is to find out what kind of compliments are used towards these famous individuals and which insults are used against them. As stated in the introduction, my hypothesis is that the sexual preference of the chosen individuals will influence the expressives social media users employ towards them. In other words, I expect some users to write, for instance, insults such as "You are a faggot". This insult, of course, would be aimed to Neil Patrick Harris, as he is the homosexual person chosen in this paper. On the contrary, my expectations with Donald Trump are that he will not get insults related to his sexual preference. Instead, I believe he will get insults related to his status as the president of the United States.

Furthermore, the analysis of this paper will use random people's comments as a source of random, public compliments and insults. The identity of these individuals will not be published as I want to preserve anonymity and ensure confidentiality. Therefore, I will only quote textual data as examples to illustrate the compliments and insults under analysis, which will be marked in bold. All the names and photographs of fans have been eliminated and replaced by the noun Fan, followed by a letter for the compliments section, and User, followed by a letter for the insults section.

\subsection{DATA SELECTION}

When looking for the sample data, posts which could contain a higher number of comments were the main objective to choose. This way, I selected nine pictures and one 
video posted on Facebook. The chosen video displays Neil Patrick Harris together with his family, wishing good morning to his fans. Regarding pictures, the first one is a picture uploaded by the actor in which he can be seen with his husband in a ceremony. Later we find a Christmas photograph which shows Donald Trump and his wife, Melania Trump, wishing merry Christmas.

Also, Donald Trump appears in another picture talking to another politician with a cheerful attitude. The President of the United States also uploaded another picture chosen for this paper in which we can see the wall that he promised to build between the United States and Mexico. Additionally, I chose a photograph uploaded by Neil Patrick Harris in which he can be seen with his family on holidays. Moreover, I chose a picture uploaded by Donald Trump in which he talks about one of his rallies. Another photograph uploaded by the president shows a reminder of the Martin Luther King Day. Furthermore, I decided to choose another picture of Trump with his wife in what it seems to be a rally. Finally, a photograph showing the car of the president was chosen.

These posts did not display the same amount of reaction by Facebook users, as some of them had three thousand comments and others had ninety-eight comments. I also kept this in mind, since I did not want to only select mainstream posts. Therefore, we have eighteen examples, in which eighteen different social network users comment a total of ninety-eight words that have been analysed, as well as four emoticons/emojis. Within the results and analysis sections, these examples have been classified into four parts: explicit compliments, implicit compliments, explicit insults, and implicit insults. The first section, explicit compliments, has six samples. The second section, implicit compliments, contains three samples, as well as the third section (explicit compliments) and the fourth section (implicit compliments).

\section{RESULTS AND ANALYSIS}

In order to analyse the samples selected, the following lexico-grammatical patterns for formulaic compliments developed by Maíz-Arévalo (2010: 983) have been chosen:

i. Exclamative clause with an adjective group modifying complimented item.

ii. Declarative clause with the complimentee in the subject position, followed by a copulative verb and a positive adjective.

iii. Declarative clause with the complimenter in the subject position, followed by a mental process of 'liking' and the complimented item in the direct object position.

This made Maíz-Arévalo and García-Gómez (2013) argue in favour of the system of compliments below (Fig. 1): 


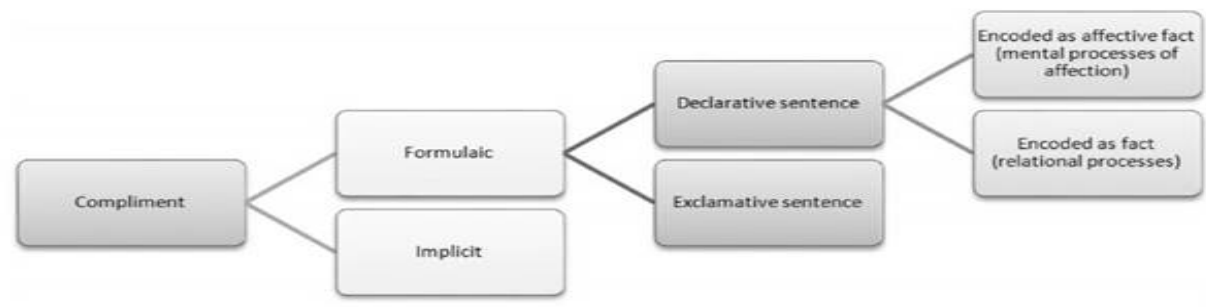

Figure 1. "System of Compliments" (Maiz-Arévalo, C. and García-Gómez, A. 2013: 741).

\subsection{EXPLICIT COMPLIMENTS}

The first category of compliments to be analysed is the explicit compliments one. As mentioned in the theoretical background section, Adachi (2011) and Boyle (2000) define explicit compliments as the ones where speakers employ the literal meanings encoded in words or phrases, or the ones where speakers compliment by using a small set of conventional formulae. The main function of these compliments is to appreciate a good skill, characteristic, or possession from the hearer, as well as praise and admire them (Holmes, 1988; Herbert, 1990). Nonetheless, these functions must be always performed through the use of literal meanings or a small set of conventional formulae, as previously stated.

Because of their linguistic realisation, any speaker would also recognise the examples shown below as explicit compliments (Maíz-Arévalo, 2012). Furthermore, and as shown by several authors ${ }^{5}$, there is a finite amount of verbs that can be used, such as love or like. Explicit compliments, as the inspection of the data set shows, are the most frequent type of compliment -we could find four explicit compliments every five compliments inspected-. Therefore, the identification and explanation of explicit compliments are shown in this section. In order to identify and explain the first pattern (i), we can find two compliments from fans addressing Neil Patrick Harris. We can observe how the first pattern (i) is mainly used to admire two aspects of the complimentees: their families, and their pictures. These functions are accomplished through the use of the following structure: exclamative clause with an adjective group modifying complimented item.

5 Boyle, 2000; Herbert and Straight, 1989; Holmes, 1998; Knapp et al., 1984, as well as several other studies regarding English varieties. 


\section{Example 1:}

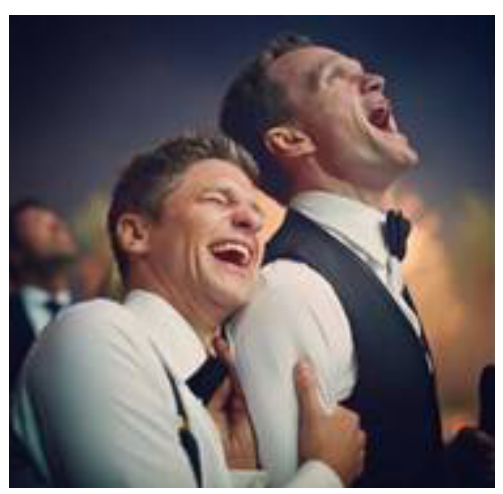

Fan A: What a beautiful pic!

This example shows a picture of Neil Patrick Harris and his husband in a cheerful attitude during a ceremony. Fan A flatters the actor's picture, and in order to do so, uses a sentence with the following structure: exclamative clause with an adjective group modifying complimented item. Its function is to admire the uploaded picture, as well as the two people that appear in it. This is accomplished through the use of the comment "What a beautiful pic!" together with a purple heart emoji (\$).

\section{Example 2:}

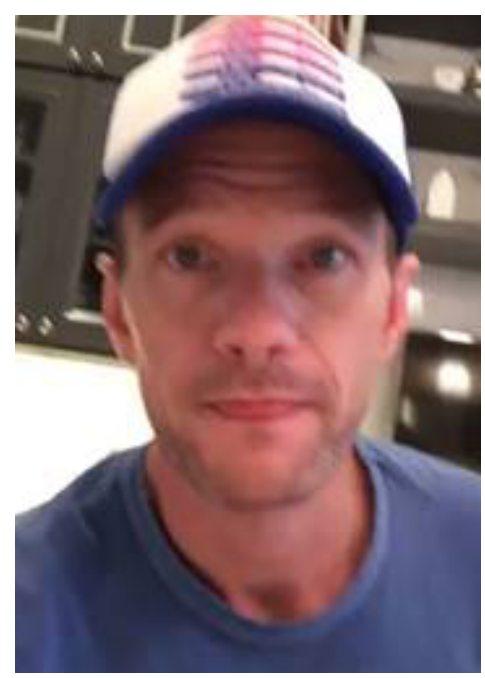

Fan B: Thank you, you made me smile. What a wonderful family! 
Example 2 shows a video uploaded by the same actor in which he wishes his fans a good morning. He also records his children and his husband singing and having a good mood. Fan B compliments the family of Neil Patrick Harris by utilising a sentence with the same structure as the previous example: exclamative clause with an adjective group modifying complimented item. This compliment's function is to flatter the people that appear in the video, who are Neil Patrick Harris, his husband, and their children. To execute this function, Fan B comments "What a wonderful family!".

Moreover, two compliments have been chosen to show the second pattern (ii). Their main function is to flatter two aspects of the complimentees: their performance at their job (a quality), and their families. To achieve these functions, the complimenters employ the following structure: declarative clause with the complimentee in the subject position, followed by a copulative verb and a positive adjective.

\section{Example 3:}

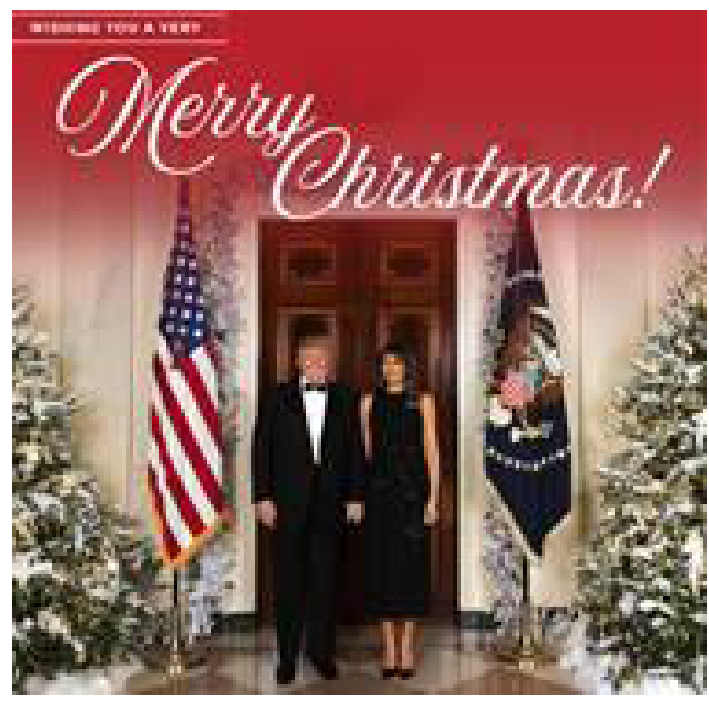

Fan C: Merry Christmas Mr. President, First Lady, and Family!!! I served under President Reagan and you sir are the best President since then..

Example number 3 displays a picture uploaded by Donald Trump. In it we can see a Christmas card with the text "Merry Christmas!" as well as the President and the First Lady. Fan C compliments Donald Trump through the use of the following structure: declarative clause with the complimentee in the subject position, followed by a copulative verb and a positive adjective. The function that this compliment carries out is to admire the performance of Donald Trump as President of the United States. This is achieved by the statement "you sir are the best President". 


\section{Example 4:}

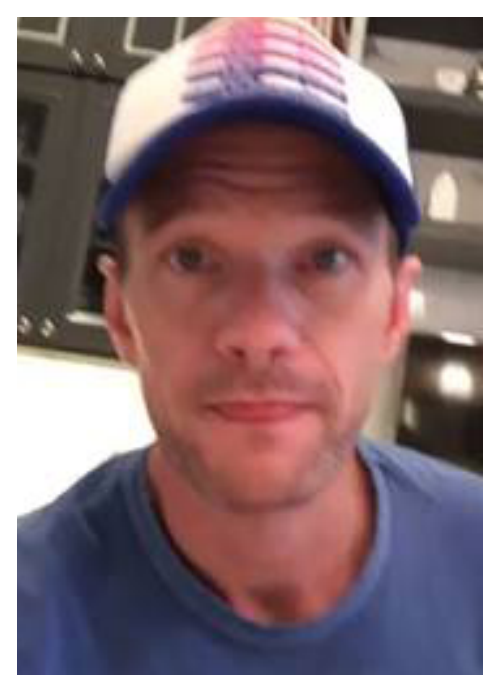

Fan D: You are adorable! Good morning for everybody!

The fourth example also appears in the same post as in Example 2. Patrick Harris uploaded video shows his family and him wishing a good morning to his fans. In this example, Fan D flatters the actor and his family through the use of the same structure as in Example 3: declarative clause with the complimentee in the subject position, followed by a copulative verb and a positive adjective.

This compliment's function is to admire the family formed by Neil Patrick Harris, his husband, and their children. We find evidence for this in the compliment "You are adorable!" We can infer that Fan D uses "you" to compliment the whole family and not just the actor. This is due to the statement of "Good morning for everybody" next to the compliment.

In the following two compliments, we can also observe the structure of the third pattern (iii). The third pattern's main function is to praise the complimentee, and in order to achieve this goal, the complimenter employs the following structure: declarative clause with the complimenter in the subject position, followed by a mental process of 'liking' and the complimented item in the direct object position. 


\section{Example 5:}

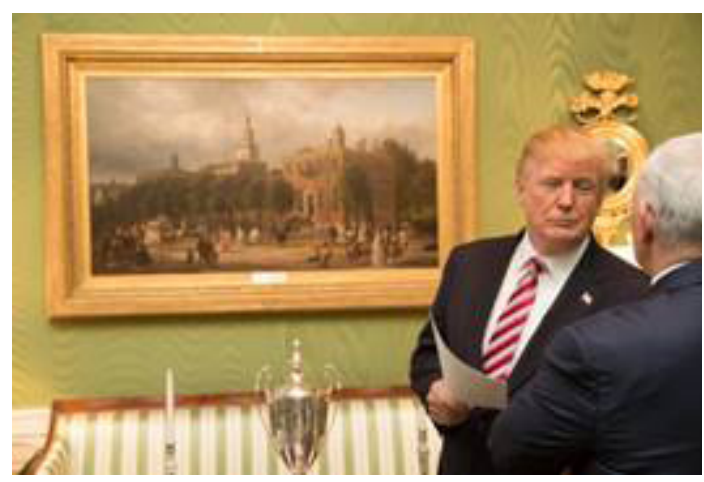

\section{Fan E: I love our President!!}

The fifth example is taken from a picture uploaded by Donald Trump in which he can be seen having a conversation with another politician. The president gets praised by Fan E, who utilises the following structure to compliment Trump: declarative clause with the complimenter in the subject position, followed by a mental process of 'liking' and the complimented item in the direct object position. The function accomplished by this compliment is to praise Donald Trump. In order to execute this function, Fan E writes "I love our President!!" in the comments section of this post.

\section{Example 6:}

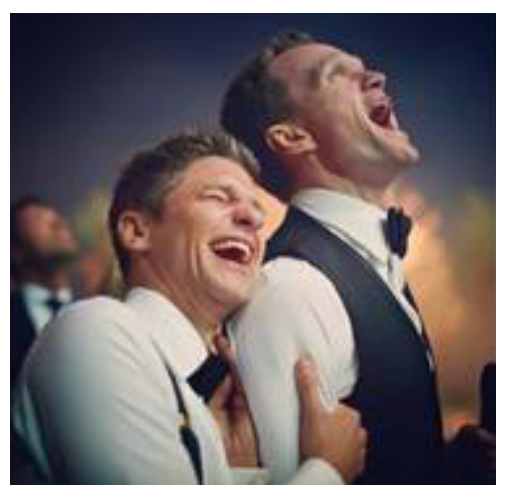

Fan F: I love you NPH

As in Example 1, we can see a picture uploaded by Neil Patrick Harris in which the actor and his husband appear. The actor gets praised by Fan F, who employs the same structure as the previous example: declarative clause with the complimenter in the subject position, 
followed by a mental process of 'liking' and the complimented item in the direct object position. Regarding the function that this compliment carries out, we can find praising, as well as in the previous example. To accomplish this, Fan F writes "I love you NPH", initials that stand for "Neil Patrick Harris".

Moreover, a new feature that social media presents is the appearance of emoticons and emojis. These elements are images formed by symbols such as punctuation marks, as well as small digital icons, which are utilised to express a particular emotion ("Emoticon", n.d.; "Emojis", n.d.) Since their creation, these images have become as popular as to be used by $92 \%$ of the online population in their everyday communication (Vickery, 2017). Therefore, we can also find emoticons or/and emojis among the comment sections in Facebook. Regarding explicit compliments in this paper, emoticons or/and emojis have shown to accomplish the function of complimenting the uploaded picture, as well as emphasising the words used in the comment, as in the following example:

\section{Example 7:}

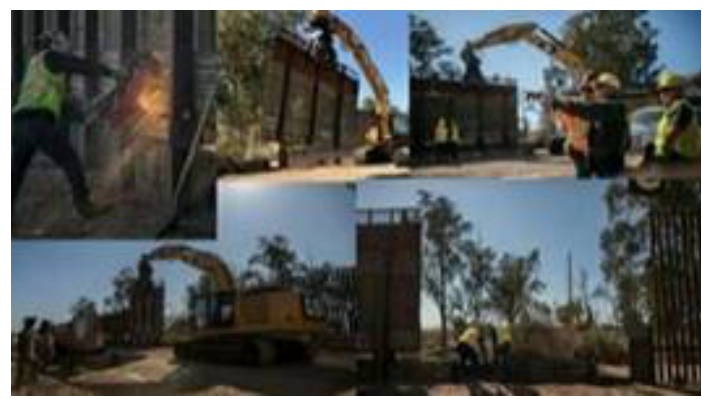

Fan $G$ :

Example 7 is taken from a picture uploaded by Donald Trump in which we can observe the construction of the wall he promised to build. Fan $\mathrm{G}$ flatters the picture by only using an emoji, without any text. The function of this emoji is to compliment Trump's picture. This is achieved by posting a smiling face with heart-eyes emoji ( $\left.{ }_{0}\right)$.

Moreover, in the first example of this section, Example 1, we can also find an emoji among a comment. In this example, a picture of Neil Patrick Harris and his husband is uploaded. Fan A not only flatters the actor's picture by the employment of text ("What a beautiful pic!") but also by the use of an emoji. The function of this emoji is to emphasise the words used in the comment. This function is carried out by the use of a purple heart emoji ( ) after the written message.

\subsection{IMPLICIT COMPLIMENTS}

In the previous section it has clearly seen how formulaic compliments can be structured. Even though they are the most frequent type of compliments, not all kinds of compliments 
need to have those fixed linguistic form. In this way, while inspecting the data set, we could find one implicit compliment every five compliments inspected, approximately. As previously seen, implicit compliments are the ones which use non-conventional meanings that can vary depending on the context of the conversation or under the influence of the Gricean maxims (Adachi, 2011; Boyle, 2000). Furthermore, Maíz-Arévalo (2012) states that the functions that they achieve are showing sincerity and building up rapport between interlocutors. However, the functions found in this analysis differ from the ones MaízArévalo claimed, as we find the aim to flatter the complimentee's personality or appearance, together with admiring the complimentee's family. To identify and analyse this phenomenon, we can take a look at the following samples from social media:

\section{Example 8:}

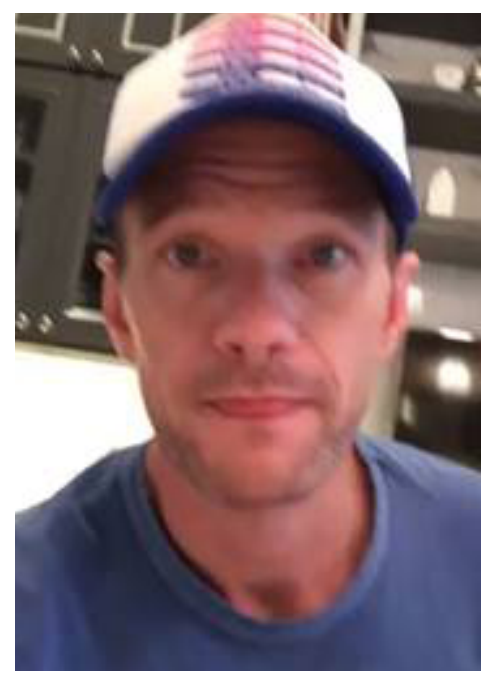

\section{Fan H: I wish I were gay just to get a chance at him...!}

This example is taken from a video uploaded by Neil Patrick Harris in which he appears with his family. Fan H, a male, expresses his positive opinion about the actor's personality or appearance. In order to do this, he uses the following structure: subject, present simple tense of the verb "to wish", followed by the same subject and the past simple tense of the verb "to be", and a noun phrase. This example is classified as an implicit compliment, and, as Maíz-Arévalo claims (2012), implicit compliments do not need to have a fixed structure as explicit compliments do. However, we can see a pattern that is not only followed by this example, but by another one from another fan ("I wish I was guy too!"). Even though is only two comments that present this pattern, it is the most frequent one among the implicit compliments of this paper. In addition, the function of the sentence presented in Example 8 is to flatter the complimentee's personality or appearance, and this is achieved by stating "I wish I were gay just to get a chance at him...!"”. 
Moreover, this sentence seems to have different interpretations. On the one side, this fan could not only be complimenting the actor but also gay people, as, to be together with the celebrity -Fan H says-, he would have to be gay. But on the other side, this fan is stating that he wishes something "just" to get a chance at the actor, therefore he is maybe rejecting everything is related to gay people but Neil Patrick Harris.

Furthermore, Fan H's comment got replies from other users. For instance, a woman commented "Funny!! I wish I was guy too! Wait! Im a girl! Lol ok ok this is confusing! ! His just super adorable! Btw ppl! Relax! It is all in good fun!” Also, another man commented "If I were gay, I would love to be with him. That is just not something I can get into. Too gay for me."

\section{Example 9:}

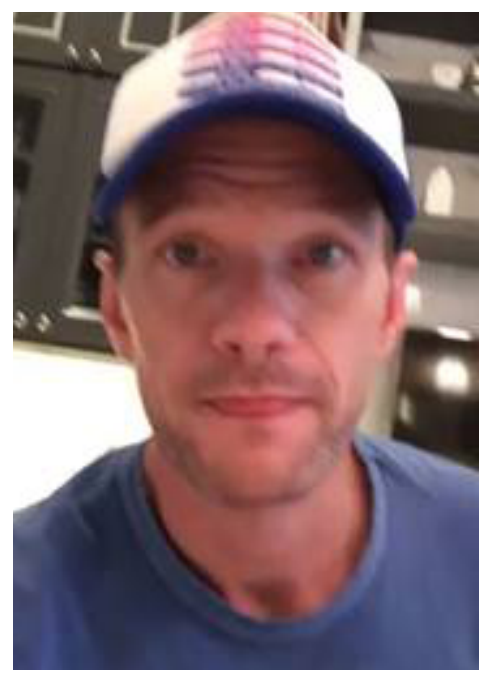

Fan I: I'm not dealing very well to this. Think I just died with cuteness. *_*

This example shows the video uploaded by Neil Patrick Harris in which he records himself and his family wishing good morning to his fans. The shown comment is posted by Fan I, a female, because she likes the actor and his family. In this case, the structure used is not repeated in other comments, but exclusively in this one. This may be due to the use of exaggeration and saying the opposite of what the speaker means. Therefore, we need to infer the meaning of her comment, as we do not have a pattern to think of in order to understand Fan I's words. Surely, Fan I is not dealing bad to this video, and she is not dying with cuteness because of it. Here, we find an example of how a negative sentence such as "I'm not dealing very well to this" and a verb like "die" can be used as something as positive. Thus, the function of this compliment is to admire both Neil Patrick Harris and his husband, together with their children. This function is carried out through the use of the comment "I'm not dealing very well to this. Think I just died with cuteness. *_*". 
Moreover, an element that reinforces the positive opinion towards Neil Patrick Harris is the emoticon "*-*". At the very end of this example, it is seen how Fan I uses an emoticon of a face with an amazed expression with the aim of flattering the family of the actor. The function of this emoticon is to reinforce the positive opinion of Fan I's comment, in the case that someone does not understand the real meaning of "I'm not dealing very well to this. Think I just died with cuteness.".

\section{Example 10:}

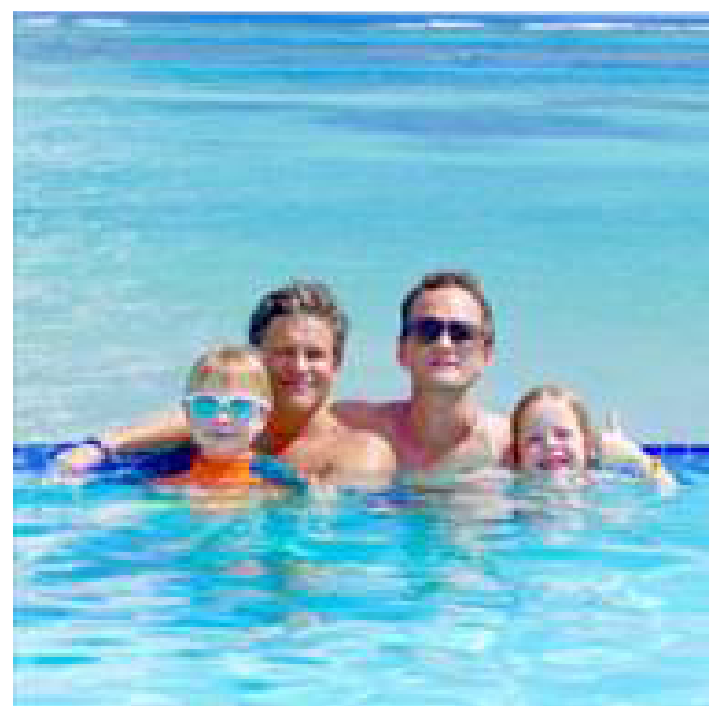

Fan J: Another picture of how children of Gay couples are miserable....oh...wait...

The tenth example is taken from a picture uploaded by Patrick Harris. It shows the actor and his family during holidays. Fan J, a male, thinks that they are a nice family. To transmit this thought, he uses irony by mocking what homophobic individuals usually state to criticise homosexual parents and their chances to raise children properly. Regarding structure, Example 10 is the only one that shows this structure. Maybe this occurs because Fan J employs irony to compliment the actor, while other fans do not use irony. The function of this compliment is to admire the actor's family. This is achieved by the use of this humoristic and critical statement: "Another picture of how children of Gay couples are miserable.... oh... wait...” Dews, Kaplan, and Winner (1995) argue that irony can be used with the aim of a positive evaluation, even if it is employed through a negative statement. These authors (1995: 348) exemplify this use with a context in which the speaker states "Terrible game" to a team has just effortlessly won a match. Nonetheless, the implicit compliments' section is too wide to be analysed in this paper. It may be a potential topic for future texts. 


\subsection{EXPLICIT INSULTS}

Although Maíz-Arévalo (2010) presented the three lexico-grammatical patterns used to analyse explicit compliments in a previous section, they can also be employed to analyse explicit insults, which are the most frequent type of insult. Thus, I have identified three lexico-grammatical patterns among explicit insults:

i. Exclamative clause with an adjective group modifying insulted item.

ii. Declarative clause with the insulted in the subject position, followed by a copulative verb and a negative adjective.

iii. Declarative clause with the insulter in the subject position, followed by a mental process of 'disliking' and the insulted item in the direct object position.

The elements that change from the three patterns previously mentioned are the negative ones. This is due to the positive intention that compliments have, which insults avoid achieving as their main aim is to offend ("Insult", n.d). Therefore, the functions that the explicit insults shown below carry out are to criticise the insulted person's personality and/ or actions. In order to identify these three lexico-grammatical patterns, three comments are analysed below:

\section{Example 11:}

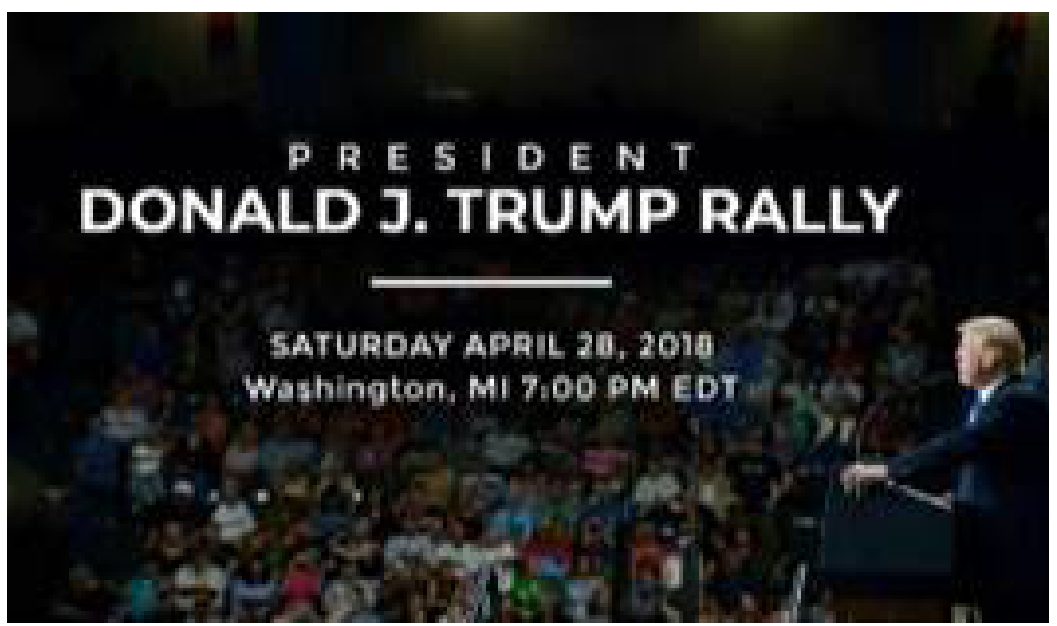

\section{User $K$ : What a dolt!}

Example 11 shows a picture uploaded by Donald Trump in which he promotes one of his rallies. User $\mathrm{K}$ does not like Trump and writes an insult with the following structure: exclamative clause with an adjective group modifying insulted item. The function of this insult is to criticise Trump's personality or actions. This is accomplished by commenting "What a dolt!". 


\section{Example 12:}

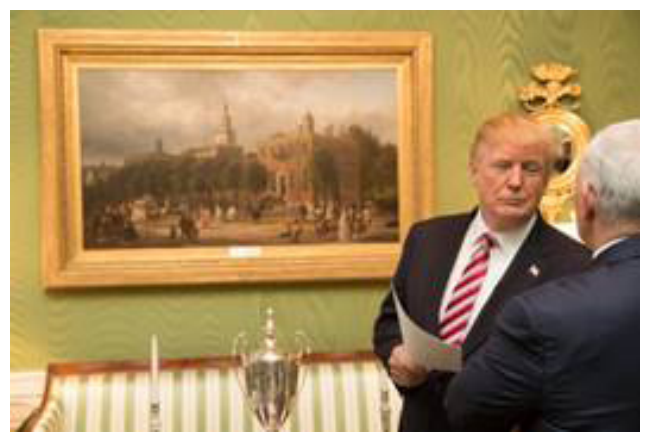

User L: You still haven't mentioned the enormous March For Our Lives demonstrations! Millions of people took to the streets, on all seven continents, in support of gun reform, and you haven't said one word about it. A real president represents ALL people, not just the party they ran as. (Remember, you first ran as Reform Party, and was a Democrat for years). The March For Our Lives brought out people of all beliefs, races and political affiliations and ages, yet not one word from you about them!!! You are a horrible person. You don't lead. You behave as if you smash and cut down, it leaves you standing. It doesn't work that way in America. Your tactics won't work here. We will survive you.

In this example, Donald Trump uploads a picture in which he can be seen talking to another politician. User L writes, among other thoughts, an insult -in bold- with the following structure: declarative clause with the insulted in the subject position, followed by a copulative verb and a negative adjective. As well as the previous example, the function that this insult achieves is to criticise the personality or the actions of the President of the United States. User L accomplishes this by writing the comment "You are a horrible person".

\section{Example 13:}

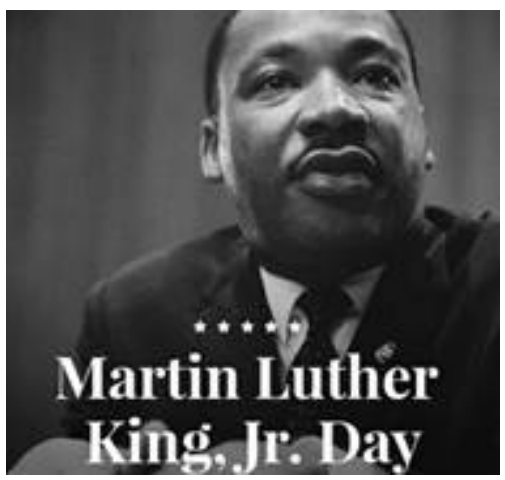

User M: We hate you. 
Example 13 presents a picture posted by Donald Trump in which we can observe the face of Martin Luther King as a way of honouring him on his day. User M insults the president following this structure: declarative clause with the insulter in the subject position, followed by a mental process of 'disliking' and the insulted item in the direct object position. The function of this insult is to criticise the personality of Trump. In order to insult the president, User M writes "We hate you".

Apart from these three examples, we can also see explicit insults carried out through emoticons and/or emojis. In this paper, their main function is to offend the insulted person, as well as his/her family, such as in the following example:

\section{Example 14:}

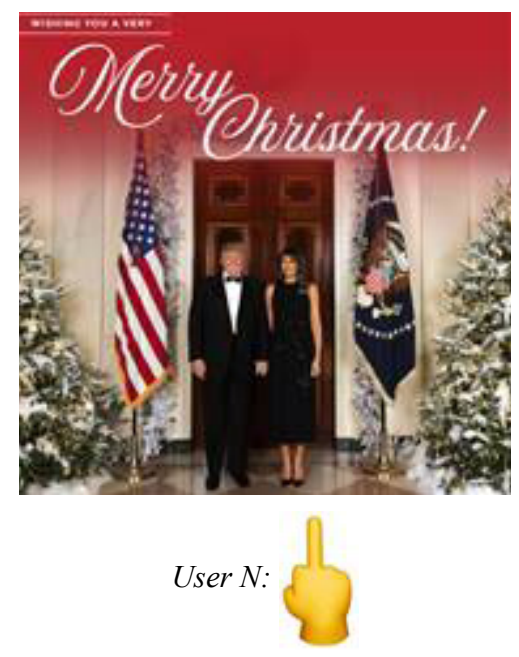

In this example we find a picture uploaded by Donald Trump. In it we can see him and his wife, as well as the message "Merry Christmas!". User N writes an emoji to show dislike towards Trump and his wife. The function of this emoji is to offend the insulted person, as well as his family. This is exclusively achieved through the employment of the reversed hand with a middle finger extended emoji $(\biguplus)$.

\subsection{IMPLICIT INSULTS}

Besides compliments, insults can also be transmitted implicitly. This means that they do not necessarily have to show a fixed linguistic form and can be understood by the context of the conversation. The examples analysed below present different structures which are not followed by any other comment; therefore, we can find how infrequent it is to write implicit insults following a fixed linguistic form -one out of thirty insults followed each one of the structures mentioned below, according to the inspection of the data set-. The functions these examples accomplish are to offend, criticise the personality or actions of the insulted person, or wishing him/her a negative event. 


\section{Example 15:}

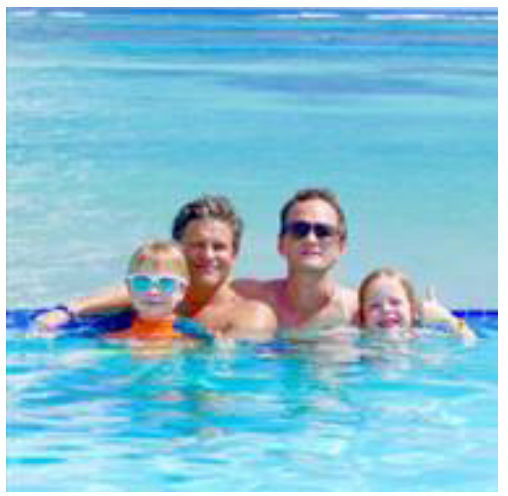

User $O$ : Where is the mother?

Neil Patrick Harris' uploaded picture shows his husband, together with him and their children, and the caption "\#TBT to last week - no work, meetings, smartphones, or responsibilities. Just family. And infinity pools. Thanks again@ @ clubmedofficial \#clubmedpuntacana". User O writes a comment which offends the actor with the following structure: interrogative clause formed by an adverb, followed by the present simple tense of the verb "to be" and a noun phrase. This structure is exclusively employed in this insult, as it was not found in any other comment. Therefore, we find how infrequent is to find an insult with this structure -one out of thirty examples showed this structure, according to the inspection of the data set-. In this case, this question can be identified as an insult because, for a homosexual couple, it could be offensive that someone takes for granted that one of them is not the parent of the children. Whether User O knows the sexual preference of the actor, it is unknown; however, the function of this insult is to offend the insulted person. This function is accomplished by the comment "Where is the mother?".

\section{Example 16:}

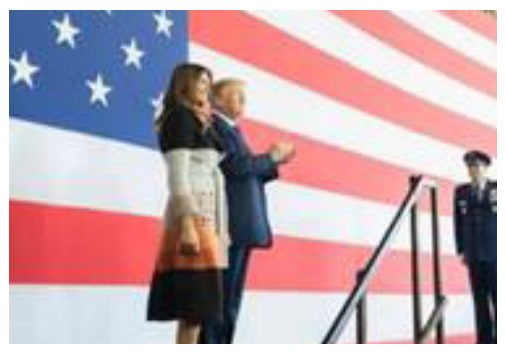

User P: You all know that trump fantasizes about banging his daughter, right? He's been making public statements about this for years! 
Example 16 shows a picture posted by Donald Trump in which he can be seen together with his wife. User P offends Trump by using two sentences in which it is made clear that the president would like to commit incest by having sex with his daughter. The structure that this insult presents is not used in any other insult, so we can see how infrequent is to find an insult with this structure -one out of thirty examples showed this structure, according to the inspection of the data set-. The function this insult accomplishes is to criticise the personality or actions of the insulted person. This function is carried out by writing "You all know that trump fantasizes about banging his daughter, right? He's been making public statements about this for years!". The evidence why we know that this is an insult is because the practice of incest is forbidden and not well seen by the society of our culture.

\section{Example 17:}

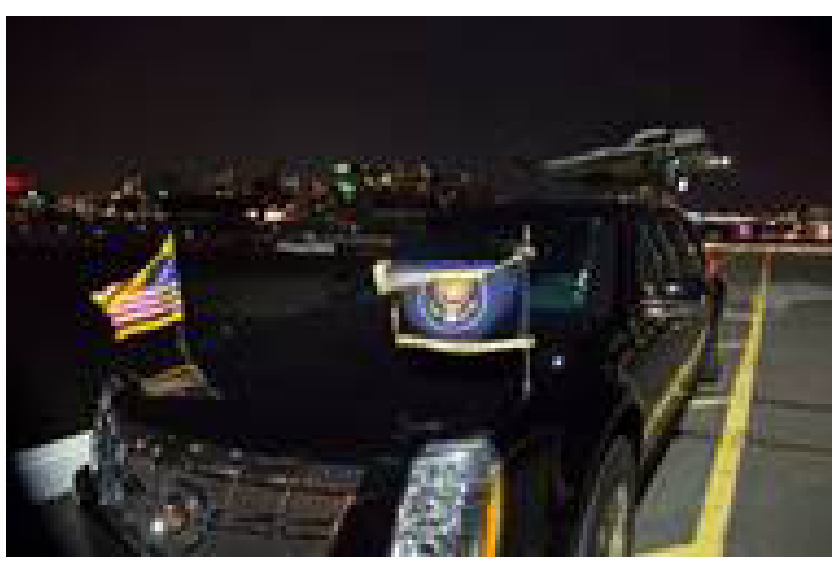

\section{User Q: Hope it crashes}

The picture of this example displays the car used by the President of the United States. User Q writes an insult which presents a structure unseen in the rest of implicit insults. This tells us how rare fixed linguistic forms are among implicit insults -one out of thirty examples showed this structure, according to the inspection of the data set-. The function of this comment is to wish a negative event to the insulted. User Q achieves this by writing "Hope it crashes". Whether he wishes that with Trump inside the vehicle or not, it is unknown, but still, we can agree that hoping a car crashes is offensive.

Additionally, among implicit insults can also appear emoticons or emojis. In the following example, we find how emoticons can reinforce the criticism towards the personality or actions of a person. 


\section{Example 18:}

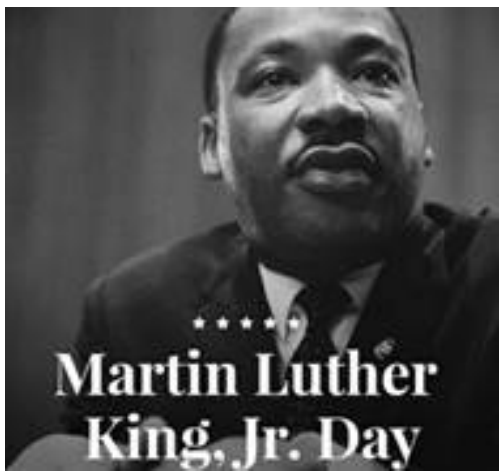

User R: Yes Donald, Dr MLK was a "Great American Hero." Too bad he would have been rejected at one of your properties based on skin color. (-); (-)

In this picture uploaded by Donald Trump the face of Martin Luther King can be seen, together with a caption which shows the following message: "Today we honor the memory of a GREAT American hero, the Reverend Dr. Martin Luther King, Jr. America is stronger, more just, and more free because of his life and work". User R criticises Trump racist thoughts by writing a message and using an emoji. The function of this emoji is to strengthen the irony of the comment. This is achieved by posting the emoji after the ironic message, so that it can "bust" the President of the United States and his attitude against non-white people.

\section{CONCLUSIONS}

My research objective for this paper was to know how compliments and insults are built in social networks posts and which functions they have, as well as answering these questions: What kind of compliments do fans use? What kind of insults do users employ? Do they change depending on the sexual preference of the celebrity that social networks users address? The analysis has revealed that fans employ both explicit and implicit compliments. Indebted to Maíz-Arévalo (2010), I have argued that explicit compliments display three different patterns:

i. Exclamative clause with an adjective group modifying complimented item.

ii. Declarative clause with the complimentee in the subject position, followed by a copulative verb and a positive adjective.

iii. Declarative clause with the complimenter in the subject position, followed by a mental process of 'liking' and the complimented item in the direct object position.

Explicit compliments are the most frequent type of compliments -there is one explicit compliment every five compliments-, and their functions are to compliment the families and 
pictures of the addressees, as well as their performance at their job (a quality) and praising the complimentees. Regarding implicit compliments, they showed how compliments can be transmitted without following a fixed linguistic form, even though we found a structure which was slightly more frequent than the other ones: subject, present simple tense of the verb "to wish", followed by the same subject and the past simple tense of the verb "to be", and a noun phrase. Interestingly, their functions were different from the ones Maíz-Arévalo (2012) claimed. In our case, implicit compliments were aimed to flatter the complimentees' personality or appearance, together with admiring the complimentees' families.

Two realisations of insults were identified: explicit and implicit insults. The explicit type of insults showed similar patterns as the explicit compliments. Nonetheless, they suffered a change from positive to negative elements, concluding with the following structures:

i. Exclamative clause with an adjective group modifying insulted item.

ii. Declarative clause with the insulted in the subject position, followed by a copulative verb and a negative adjective.

iii. Declarative clause with the insulter in the subject position, followed by a mental process of 'disliking' and the insulted item in the direct object position.

This type of insult was aimed at criticising the insulted person's personality and/ or actions. Furthermore, as well as implicit compliments, implicit insults showed how a person can offend without following a fixed linguistic form. However, implicit insults did not show a more frequent structure like implicit compliments did. This occurred because each of the insults was the only one which presented its corresponding structure -one out of thirty, according to inspection of the data set-. The functions implicit insults accomplish are to offend, criticise the personality or actions of the insulted person, or wishing her/him a negative event.

Something the appearance of new elements among compliments and insults was not expected: emoticons and emojis. These small images can be used on their own or together with text, and the functions they carry out are to compliment a picture or to strengthen the opinion of the fan -in the case of compliments-. Regarding insults, their functions are to offend the insulted person as well as his/her family, or to strengthen the idea inside the written message.

Although one may expect that compliments and insults were used in simple sentences, as social networks are usually non-formal webpages, the analysis has shown that a wide range of structures, both in compliments and insults, were used. Moreover, compliments and insults could seem simple, but, sometimes, they ended up being the totally opposite type of expressive, as irony could appear. Furthermore, my hypothesis was that the sexual preference of the chosen famous characters will strongly influence social networks users when commenting on their posts. Nonetheless, this only occurred in two occasions. First, when a fan wished to have the same sexual preference as the actor Neil Patrick Harris. And second, when a Facebook user did not understand -or did not want to understand- that the actor is a homosexual individual with a husband and children. Obviously, in the case that the user knew the sexual preference of Patrick Harris, this example ("Where is the mother?") would have been classified as an insult. However, in the case that this user did not know 
about the sexual preference of the actor, this example would still have been classified as an insult. This is due to the function of offending that the comment carries out, as it is not pleasant for a homosexual, male couple to read that their children need a mother to be happy. By this example, we illustrate how a comment can be classified as an insult, even though it was not meant to be an offensive comment.

\section{REFERENCES}

ADACHI, C. 2011. A Sociolinguistic Investigation of Compliments and Compliment Responses among Young Japanese. The University of Edinburgh.

Al-Azzawi, J. N. 2011. Compliments and Positive Politeness Strategies. The Open Educational College.

Austin, J. L. 1962. How to Do Things with Words. London: Oxford University Press.

BACH, K. \& HARnish, R. M. 1982. Linguistic Communication and Speech Acts. The MIT Press.

Bernal, M. 2008. Do Insults Always Insult? Genuine Impoliteness Versus Non-genuine Impoliteness in Colloquial Spanish. International Pragmatics Association, 18(4), 775-802. Retrieved from https://www.researchgate.net/publication/273513260_Do_ insults_always_insult_Genuine_impoliteness_versus_non-genuine_impoliteness_in colloquial_Spanish

Boyle, R. 2000. "You've Worked with Elizabeth Taylor!”: Phatic Functions and Implicit Compliments. Applied Linguistics, 21 (1), 26-46.

Bravo, D. 2003. Actividades de Cortesía, Imagen Social y Contextos Socioculturales: Una Introducción. In Bravo, D. (ed.), La Perspectiva No Etnocentrista de la Cortesía: Identidad Sociocultural de las Comunidades Hispanohablantes. Stockholm: Actas del Primer Coloquio del Programa EDICE. 96-108.

Brown, P. \& Levinson, S. 1987. Politeness: Some Universals in Language Usage. Cambridge: Cambridge University Press.

CulpePer, J. 2005. Impoliteness and Entertainment in the Television Quiz Show: The Weakest Link. Journal of Politeness Research, 1(1). 35-72. DOI: 10.1515/ jplr.2005.1.1.35

“Donald TrumP” 2018. In Biography. March 01. Retrieved from https://www.biography. com/people/donald-trump-9511238

Dews, S., Kaplan, G., Winner, E. 1995. Why Not Say It Directly? The Social Functions of Irony. Discourse Processes, 19. 347-367.

Eelen, G. 2001. A Critique of Politeness Theories. Manchester: St. Jerome.

Eelen, G. 2014. A Critique of Politeness Theory, Vol. 1. Routledge.

“Emou”". N.d. In English Oxford Living Dictionaries. Retrieved from https:// en.oxforddictionaries.com/definition/emoji 
“ЕмотісоN”. N.d. In Cambridge Dictionary. Retrieved from https://dictionary.cambridge. org/es/diccionario/ingles/emoticon

Fernández F. A., \& Rosa M. J.C. 2003. Semantic Derogation in Animal Metaphor: A Contrastive-Cognitive Analysis of Two Male/Female Examples in English and Spanish. Journal of Pragmatics, 35. 771-797.

Golato, A. 2005. Compliments and Compliment Responses. Grammatical Structure and Sequential Organization. Amsterdam; Philadelphia: John Benjamins Publishing Company.

Gordon, K. N.d. Social media - Statistics \& Facts. Retrieved from https://www.statista. com/topics/1164/social-networks/

Grice, P. 1991. Studies in The Way of Words. Harvard University Press.

“HashtaG”. N.d. In Cambridge Dictionary. Retrieved from https://dictionary.cambridge. org/es/diccionario/ingles/hashtag

Herbert, R. K. 1990. Sex-Based Differences in Compliment Behaviour. Language in Society. Cambridge University Press, 19 (2), 201-224.

Herbert, R. \& K., Straight, H. S. 1989. Compliment-Rejection versus ComplimentAvoidance: Listener-Based versus Speaker-Based Pragmatic Strategies. Language and Communication, 9 (1), 35-47.

Holmes, J. 1986. Compliments and Compliment Responses in New Zealand English. Anthropological Linguistics, 28 (4), 485-508.

Holmes, J. 1998. Paying compliments: A Sex-Preferential Positive Politeness Strategy. Journal of Pragmatics, 12, 445-465.

Holmes, J. 2013. Women, Men and Politeness. London and New York: Routledge.

Hughes, G. 2006. An Encyclopedia of Swearing: The Social History of Oaths, Profanity, Foul Language, and Ethnic Slurs in the English-speaking World. London: M.E. Sharpe.

“InsulT". N.d. In Merriam-Webster Dictionary. Retrieved from https://www.merriamwebster.com/dictionary/insult

“Irony”. N.d. In Merriam-Webster Dictionary. Retrieved from https://www.merriamwebster.com/dictionary/irony

Knapp, M. L., Hopper, R. \& Bell, R. A. (1984). Compliments: A Descriptive Taxonomy. Journal of Communication, 34 (4), 12-32.

Maíz-ArÉvalo, C. 2010. Intercultural Pragmatics: A Contrastive Analysis of Compliments in English and Spanish. In Ma. L. G. Blanco, \& Marin-Arrese. J. (Eds.), Discourse and Communication: Cognitive and Functional Perspectives. Madrid: Dykinson \& Universidad Rey Juan Carlos, 175-208.

Maíz-ArÉvalo, C. 2013. "Just Click 'Like"”: Computer-mediated Responses to Spanish Compliments. Journal of Pragmatics, 51, 47-67. 
Maíz-ArÉvalo, C. 2012. “Was That a Compliment?” Implicit Compliments in English and Spanish. Journal of Pragmatics, 44, 980-996.

Maíz-Arévalo, C., \& García-Gómez, A. 2013. 'You Look Terrific!' Social Evaluation and Relationships in Online Compliments. In Discourse Studies. Madrid: SAGE Publications, 15 (6), 735-760. DOI: 10.1177/1461445613490011

Mateo, J., \& Yus, F. 2013. Towards A Cross-Cultural Pragmatic Taxonomy of Insults. John Benjamins Publishing Company. DOI: 10.1075/jlac.1.1.05mat

“NeIl Patrick Harris". 2015. In Biography. February 23. Retrieved from https://www. biography.com/people/neil-patrick-harris-224896

NorricK, N. R. 1978. Expressive Illocutionary Acts. Journal of Pragmatics, 2 (3), 277-291.

Number of Monthly Active Facebook Users Worldwide as of 4TH QuARTER OF 2017 (IN MILLIONS). 2018. In Statista. Retrieved from https://www.statista.com/statistics/264810/ number-of-monthly-active-facebook-users-worldwide/

“OFFENSIVE WORDS FOR PEOPLE ACCORDING TO NATIONALITY OR ETHNICITY”. N.d. In Macmillan Dictionary. Retrieved from https://www.macmillandictionary.com/thesauruscategory/british/offensive-words-for-people-according-to-nationality-or-ethnicity

Potтs, C. 2005. The Logic of Conversational Implicatures. New York: Oxford University Press Inc.

Reporter, D., M. 2011. How I Met Your Mother Star Neil Patrick Harris and Boyfriend Snuggle Their Surrogate Twins on Family Stroll. Mail Online. February 1. Retrieved from http://www.dailymail.co.uk/tvshowbiz/article-1352522/How-I-Met-YourMothers-Neil-Patrick-Harris-boyfriend-twins-stroll.html

SEARLE, J. R. 1976. A Classification of Illocutionary Acts In Language in Society. Cambridge University Press, 5, 1, 1-23.

TaAvitsainen, I., Jucker, A. H. 2010. Expressive Speech Acts and Politeness in Eighteenth Century English. In Hickey, R. (ed.). Eighteenth Century English: Ideology and Change. Cambridge: Cambridge University Press. 159-181.

VICKERY, N. 2017. “The Rise of Emoji Use in Social Media Marketing”. Retrieved from https://socialnomics.net/2017/05/30/the-rise-of-emoji-use-in-social-media-marketing/

WoFsOn, N. 1983. An Empirically Based Analysis of Complimenting in American English. In Wolfson, N. and Judd, E. (eds) Sociolinguistics and Language Acquisition. Rowley, Mass: Newbury House, 82-95.

Yule, G. 1996. Pragmatics. Oxford: Oxford University Press. 